\title{
Influence of the Electrolyte Salt on the Electrochemical Polymerization of Pyrrole. Effects on $p$-Doping/Undoping, Conductivity and Morphology
}

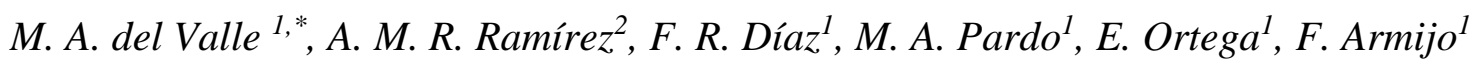 \\ ${ }^{1}$ Pontificia Universidad Católica de Chile, Laboratorio de Electroquímica de Polímeros (LEP), Av. V. \\ Mackenna 4860, 7820436-Macul, Santiago, Chile. \\ ${ }^{2}$ Universidad Mayor, Núcleo Química y Bioquímica, Facultad de Estudios Interdisciplinarios, Laboratorio \\ de Electroquímica, Av. Alemania 0281, 4801043-Temuco, Temuco, Chile. \\ *E-mail: mdvalle@uc.cl
}

doi: $10.20964 / 2018.12 .37$

Received: 7 May 2018 / Accepted: 12 September 2018 / Published: 5 November 2018

The relationship between the $p$-doping/undoping process (charge, stability and reversibility) and the nucleation and growth mechanisms concerning the influence of the type of electrochemical perturbation of the system during the electropolymerization of pyrrole (PPy) by oxidation of the monomer, is reported in the presence of different salts $\left(\mathrm{LiClO}_{4}, \mathrm{TBAClO}_{4}, \mathrm{TBAPF}_{6}, \mathrm{TEAPF}_{6}, \mathrm{LiTFMS}\right.$ or TBATFMS $)$, in acetonitrile. The characterization is conducted in situ by cyclic voltammetry or constant potential, complemented by conductivity measurements, using the four-point method, and morphological analysis employing SEM and AFM. The direct correlation between the $p$-doping/undoping process and the volume of the anion of the supporting electrolyte utilized for the electrosynthesis is thus established, in addition to the type of perturbance applied to the system (there are charge variations of up to $60 \%$ among electro-obtained PPy deposits under different experimental conditions). Furthermore, the $p$ doping/undoping process is evaluated after 1000 successive voltammetric cycles in $0.10 \mathrm{~mol} \mathrm{~L}^{-1} \mathrm{LiCl}$ aqueous solution, which allows verifying that PPy obtained by potentiodynamic method has greater stability, reversibility and charge. In summary, it is demonstrated that the electrochemical technique, under the working conditions, as well as the size of the anion and cation from the supporting electrolyte, determine the morphology of the deposited polymer and possess an intrinsic relationship with the $p$ doping/undoping process, responsible for the macroscopic properties of these materials, e.g. conductivity. This allows the experimental conditions to model according to the required properties to the application that will be given to the polymer deposit.

Keywords: Polypyrrole, electrosynthesis of polypyrrole, morphology and conductivity of polypyrrole, properties of conducting polymers. 


\section{FULL TEXT}

(C) 2018 The Authors. Published by ESG (www.electrochemsci.org). This article is an open access article distributed under the terms and conditions of the Creative Commons Attribution license (http://creativecommons.org/licenses/by/4.0/). 